\title{
Linking counterfactuality with theory of mind: evidence from developmental studies with Yàobúshì in Chinese
}

\author{
Ching-fen Hsu
}

\author{
Correspondence: \\ chinghsu@cc.hfu.edu.tw \\ Department of Foreign Languages \\ and Literature, Huafan University, 1 \\ Huafan Road, Shiding, Taipei 22301, \\ Taiwan
}

\begin{abstract}
This paper revisits Chinese counterfactuality with 要不是 yàobúshì 'if it were not' by presenting additional data from elementary school children and high school teenagers to determine the availability of counterfactual reasoning with psycholinguistic studies. Constituent comparisons of propositional representations were hypothesized in the mental model of sentence processing. Results indicate both developmental groups processed counterfactuals with yàobúshì similarly to college students, demonstrating that the mismatch of structures and semantics does not exist in counterfactuals with yàobúshì in Chinese. Relevance to theory of mind in processing counterfactuality with Chinese as an example is proposed and discussed.
\end{abstract}

Keywords: Theory of mind, Counterfactual reasoning, Chinese, Developmental studies

\section{Introduction}

Due to the absence of morphological inflections of the subjunctive mood in Chinese, Chinese speakers use contextual information to disambiguate conditional statements from hypothetical, imaginative, or counterfactual meanings (Liu 1985; see Rafetseder and Perner 2010 in English classification). However, only a few classical Chinese words have been identified as conditional expressions, such as 假使 jiăshı̌ 'if', 若使 ruòshı̌ 'if', and 微 wéi 'if not' (Eifring 1988; Jiang 2018) and some other constructive structures, such as 如果...早就 rúguǒ...zǎojiù 'if-something should have been done' and 如果早... rúguǒzăo 'if something has been done earlier' (Jing-Schmidt 2017). Moreover, there has been little supporting evidence from psycholinguistic studies. Hsu (2013) coerced counterfactual reading with 如果 rúguó 'if' and 沒有 méiyóu 'not' in antecedent clauses, together with 不會 búhui 'not' and the aspect marker of completion le (了) in consequent clauses, demonstrating counterfactual reading by Chinese speakers from the mismatch of syntax and semantics on different developmental stages. Further investigations found that 要不是 yàobúshì 'if it were not' can serve as a counterfactual conjunction in Chinese, initiating semantic-based representations of contrary-to-fact sentences (Hsu 2014). The paper focuses on yàobúshì because it is a Chinese word that has the counterfactual lexically represents and does not require any contextual information to infer counterfactuality (Hsu 2014; Jiang 2018). Hence, it allows investigation of the development of counterfactual reasoning without the complexity of the

(c) The Author(s). 2017 Open Access This article is distributed under the terms of the Creative Commons Attribution 4.0 International License (http://creativecommons.org/licenses/by/4.0/), which permits unrestricted use, distribution, and reproduction in any medium, provided you give appropriate credit to the original author(s) and the source, provide a link to the Creative Commons license, and indicate if changes were made. 
contextual inference. This paper aims at providing (1) linguistic evidence for developmentally comprehending counterfactuals through yàobúshì and (2) a proposal for highlighting the psychological relevance of theory of mind with examples of Chinese counterfactuality with yàobúshi.

\subsection{Theory of mind}

Theory of mind is a term coined by Premack and Woodruff (1978) to describe chimpanzees' ability to understand others' minds. Wimmer and Perner (1983) conducted tasks on theory of mind in humans. Theory of mind refers to an ability to infer a full range of mental states such as beliefs, desires, intentions, imagination, and emotions (Baron-Cohen et al. 1985). The standard protocols are changes in locations and contents.

One protocol for a location change is a Sally-Anne story, which is given as the following: "Sally and Anne were playing marbles together in a room. A few minutes later, before going outside, Sally put her marble in a basket and left Anne alone in the room. Anne was very naughty. She took out Sally's marbles and put them in a box. Then, a child was asked where Sally would go to find her marbles after coming back." All the actions are presented to the participants in full view. Four-year-old children correctly point to the basket in which Sally originally put the marbles, demonstrating their ability to infer mental states from others' perspectives. Children who are younger than this age point to the box from which Anne removed the marbles after Sally was absent, showing their inability to reason others' mental states or their holding of false beliefs referenced to the present. One protocol for a content change is as follows: "The children were shown a tube of smarties and were asked what was inside. Although most children replied smarties, an experimenter opened the tube and found that there were pencils inside. Then, the child was asked what other children would think the content was inside the tube." The age threshold for passing the test is the same as the Sally-Anne story.

In these two protocols, representations are assumed to be formed in accordance with initial conditions and consequences of changes (Frye et al. 1995). The protagonist who did not see the process of location change and was not aware of the mismatch between the appearance and the reality of the tube would form a contrastive representation to the current situation, or false beliefs. To prevent the formation of false beliefs, participants applied theory of mind to shift their perspectives. The representations of initial states and changed consequences are basically in conflict and an adjustment must be made. Three-year-olds are unable to switch perspectives, thereby resulting in difficulties that lead them to make a high percentage of realistic errors.

\subsection{Causal reasoning in counterfactuality}

Errors in false-belief tasks are symptomatic of a broader difficulty with counterfactuality because of the lack of or unsuccessful causal reasoning. In the studies by Riggs et al. (1998), children 3-4 years of age listened to two stories and were required to make inferences based on a physical state and a mental state. For example: "Peter and Sally were in their house. Peter did not feel well, so he went to bed. Sally then went out shopping. After a little while, a phone rang, and Peter got the call. He was asked to help put out a fire in a post office. Therefore, Peter went out. Sally went home after finishing shopping." The children were asked a physical state question: "If there had been no fire, 
where would Peter be?" and a mental state question: "Where does Sally think Peter was?" The children were able to recall earlier situations of the testing event. However, instead of replying with correct locations to mental state questions, 3-year-old children had difficulty in inferring contrary-to-fact conditions.

Counterfactual thoughts might be produced through unpleasant feelings or positive emotions, which, in turn, strengthen counterfactual thinking as a cognitive loop (JingSchmidt 2017; Roese 1997). The essential feature of mental states is the causal role of distinctive causes and mental or behavioral consequences (Sterelny 1990). For example, the characteristics of anger are a belief of wrongdoing and a desire to do violence. Through causal computations, for comprehenders, the narrators' intentions are interpreted and inferred, including solitary mind and others' minds; for speakers, counterfactual reasoning is beneficial to learning from experience (Liu 1985). In development, children must learn to distinguish others' minds from their own (Flobbe et al. 2008).

Following a previous study by Hsu (2014), who demonstrated that sentences with yàobúshi led to counterfactual reading in Chinese and a differentiating of realities/beliefs and imaginations/desires, this differentiation is similar to decoupling in pretend play, a cognitive concept that emerges in early childhood (Leslie and Thaiss 1992). Decoupling introduces an additional mental structure that operates on the basis of beliefs, making reasoning possible in cognition. For instance, a mother (an agent) pretends that a banana (an anchor) is a telephone (an imaginary or a pretend situation) in playing with children. This pretense evidences a mechanism of theory of mind working. It is proposed that Chinese counterfactuality with yàobúshì takes the theory of mind mechanism with decoupling reality/beliefs as antecedents and imaginations/desires as consequents, as in

\section{(1) 要不是我遲到了, 車子就不會開走了 yàobúshì_wǒ_chídào_le, chēzi_jiù_búhuì_kāizǒu_le if-it-were-not___late_ASP, car_only_would-not_drive-away_ASP If it was not that I had been late, the car would not have been driven away}

The antecedent clause states the current situation or true belief of the narrator; hence, the consequent clause describes the imaginary desire of the narrator, who wishes that the car was still there for the narrator to catch it in time. This counterfactual sentence clearly conveys the speaker's intention and feeling toward this event. Listeners comprehend the contrary-to-fact meaning and infer the speaker's mental states. Subsequently, listeners might provide possible solutions or comforting words to the narrator. Accordingly, an interpersonal social interaction arises. Without morphological inflections, the counterfactual conjunction yàobúshi allows Chinese speakers to enter into an imaginative world with social and psychological elements. The relevance of linguistic counterfactuality to psychological theory of mind is more evidenced in counterfactual reasoning in Chinese.

\section{Method}

\subsection{Participants}

Three groups of participants were recruited as follows: (1) college students $(n=20,5$ females $/ 15$ males, mean age $=20.1$ years $),(2)$ junior high school students $(n=20,13$ females $/ 11$ males, mean age $=14$ years), and $(3)$ elementary school students $(n=19,10$ 
females $/ 9$ males, mean age $=12$ years). Participants representing different developmental stages were recruited based on developmental psychologist Jean Piaget's theory of cognitive development (Piaget 1936). Based on the theory, four stages of cognitive development are proposed as follows: the sensorimotor stage (birth to 2 years old), the preoperational stage ( 2 to 7 years old), the concrete operational stage ( 7 to 11 years old), and the formal operational stage (12 years old onward). Starting from the fourth stage, children can think abstractly and form hypothetical ideas. To gain possible comparisons across developmental ages from childhood to adulthood on this issue (other than location change in the Sally-Anne story and content change in the Smarties test) and to have a workable design to truly probe counterfactual comprehension in reading (other than the cognitive development limitation of the participants), 12-year-old participants were recruited.

\subsection{Materials and design}

The stimuli were the same as those in Hsu (2014). Based on the constituent comparison model (CCM) (Chase and Clark 1972; Clark and Chase 1972; Carpenter 1973; Carpenter and Just 1975), four types of test sentences were generated with the form of a factual or counterfactual statement in an antecedent clause and a consequent clause, including factual-factual (FF), factual-counterfactual (FC), counterfactual-factual (CF), and counterfactual-counterfactual (CC). Four scenarios covering the four types of test sentences were created. Hence, there were 16 test sentences, or 32 clauses, as the stimuli.

The FF test sentences combine factual antecedents and factual consequents, e.g.,

（2）颱風來了, 機場也關閉了

táifēng_lái_le, jīchăng_yě__guānbì_le

hurricane_come_ASP, airport_also__close_ASP

The hurricane came, the airport was closed

which describes the actual state of the event in which the airport closure was due to the hurricane. In the $\mathrm{CC}$ test sentences, the counterfactual expression occurred with the conditional conjunction yàobúshì in the antecedents and the negation búhuì with an aspectual particle $了$ le in the consequents, e.g.,

（3）要不是颱風來了, 機場就不會關閉了

yàobúshì_táifēng_lái_le, jīchăng_jiù_búhuì_guānbì_le

if-it-were-not_hurricane__come_ASP, airport_only_not_close_ASP

If it wasn't that the hurricane had come, the airport would not have been closed

In the FC test sentences, the counterfactual expression occurs similarly to the consequents in the CC test sentences, with an additional conjunction, 否則 fouzé 'otherwise', to allow this sentence to be interpreted naturally, e.g.,

（4）颱風來了, 否則機場就不會關閉了

táifēng_lái_le, fǒuzé_jīchăng_jiù_búhuì_guānbì_le

hurricane_come_ASP, otherwise_airport_only_not_close_ASP

The hurricane came, otherwise the airport would not have been closed 
Here, fouzé functions as 要不然 yàobùrán 'if not so' in interpretation. In the CF test sentences, the method of expressing counterfactual meaning in the antecedents is the same as that in the $\mathrm{CC}$ test sentences, e.g.,

（5）要不是颱風來了, 機場也會關閉一陣子

yàobúshì_táifēng_lái_le, jīchǎng_yě_huì_guānbì_yízhènzi

if-it-were-not_hurricane_come_ASP,

airport_also__would__close_for-a-short-while

If it wasn't that the hurricane had come, the airport would have been closed shortly

Although the CF combination is a non-canonical sentence type in Chinese counterfactuality, to compromise with the experimental $2 \times 2$ design of clause types (factual, counterfactual) and clause positions (antecedent, consequent), CF sentence experimental materials are included. While this type of test sentence is non-canonical in Chinese counterfactuality, the participants processed this combination as a CC type of counterfactual (see the results).

To investigate the participants' understanding of each test sentence, four types of probe sentences examined truth values, and polarities were created. They were as follows:

(1) Probes with true affirmative (TA) as

颱風來了, 機場關閉了

táifēng_lái_le, jīchăng_guānbì_le

hurricane_come_ASP, airport_close_ASP

The hurricane came, the airport was closed

(2) Probes with false affirmative (FA) as

颱風遠離了, 機場開放著

táifēng_yuǎnlí_le, jīchǎng_kāifàng_zhe

hurricane_far-away_ASP, airport_open_ASP

The hurricane was far away, so the airport was open

(3) Probes with true negative (TN) as

颱風沒有遠離, 機場沒有開放

táifēng_méiyǒu_yuǎnlí, jīchǎng__méiyǒu_kāifàng

hurricane_not_far-away, airport_not_open

The hurricane was not far away, therefore the airport was not open

and

(4) Probes with false negative (FN) as

颱風沒有來, 機場沒有關閉

táifēng_méiyǒu_lái, jīchǎng_méiyǒu_guānbì

hurricane_not_come, airport_not_close

The hurricane did not come, so the airport was not closed

Each clause in the test sentences was evaluated by the four probes of its truth value. For the target clause 
（6）要不是颱風來了

yàobúshì_táifēng_lái_le

if-it-were-not_hurricane_come_ASP

If it wasn't that the hurricane had come

half of the probes were true in the TA condition, as in

（7）颱風來了

táifēng_lái_le

hurricane_come_ASP

The hurricane came

and in the TN condition, as in

（8）颱風沒有遠離

táifēng_méiyǒu_yuǎnlí

hurricane_not_far-away

the hurricane was not far away

The proposition in the TA condition was the intended meaning of the counterfactuals and contained the exact proposition 來 lái 'come' noted in the surface structures. In addition, the TN condition expressed the true meaning with a negation, falsifying the desired proposition, as in

（9）沒有遠離

méiyǒu_yuănlí

not_far-away

was not far away

The remaining probes were false in the FN condition, as in

(10) 颱風沒有來

táifēng_méiyǒu_lái

hurricane_not_come

the hurricane did not come

and in the FA condition, as in

(11) 颱風遠離了

táifēng_yuǎnlí_le

hurricane_far-away_ASP

the hurricane was far away

The FA condition incorrectly stated the desired situation as the real event, such as

(12) 颱風遠離

táifēng_yuǎnlí 
hurricane_far-away
the hurricane was far away

Thus, 128 experimental trials were presented to all of the participants who were required to respond to the truth value of matching each probe sentence and the target clause based on their comprehension. Practice trials were given before the experiment began. Filler sentences stating situations opposite to the test sentences were randomly presented.

\subsection{Procedure}

A 500-ms fixation was displayed prior to a test sentence on the screen. The participants were instructed to read each sentence and to comprehend its meaning. After a 5-s presentation of the test sentence, a probe sentence appeared. The participants clicked the mouse to decide whether the probe matched the meaning of the target clause. The buttons for yes and no responses were counterbalanced. The response latency was recorded immediately after the onset of the probe sentence. When a response was detected, the probe disappeared. The antecedent clauses were presented prior to the consequent clauses.

Based on the CCM, sentences are mentally transformed as representations according to propositions. This transformation stands for internal structures of representations in terms of propositions. The representations of a test sentence and the probed sentence are exhaustively compared from innermost to outermost propositions. A plus sign (+) is used to label a match of proposition comparison, whereas a minus sign (-) is used to tag a mismatch. Whenever a mismatch is encountered, it initiates comparisons from the beginning. This model assumes that the reinitiated comparison turns a mismatch into a match to avoid generating a loop. The last response index, as true or false, indicates the comparison result. In Table 1, the TA probes undergo different numbers of mental operations compared to the two representations from the target clause and the probe. One more mental operation is required to compare the test sentence with a false statement (FA) to comprehend factual clauses.

In Table 2, the hypothetical mental processes of counterfactual sentences with yàobúshi are given. The conjunctive yàobúshì is represented as a conditional conjunction

Table 1 Hypothetical mental operation of affirmative probe sentences compared to factual clauses

\begin{tabular}{|c|c|c|}
\hline Condition & True affirmative (TA) & False affirmative (FA) \\
\hline Target clause & The hurricane came & The hurricane came \\
\hline Test sentence & The hurricane came & The hurricane was away \\
\hline Target representation & (came, hurricane) & (came, hurricane) \\
\hline Test representation & (came, hurricane) & (far away, hurricane) \\
\hline Mental operations & $\square$ & 凶 \\
\hline Response index: false $₫$ & & + \\
\hline \multirow[t]{2}{*}{ true $\square$} & Response $=$ true & Response $=$ false \\
\hline & K comparison $(K=1)$ & $K+1$ comparisons \\
\hline Chinese text in target & 颱風來了, ......... & 颱風來了, ......... \\
\hline Chinese text in probe & 颱風來了, ......... & 颱風遠離了, ........ \\
\hline
\end{tabular}


Table 2 Hypothetical mental operation of affirmative probe sentences compared to counterfactual clauses

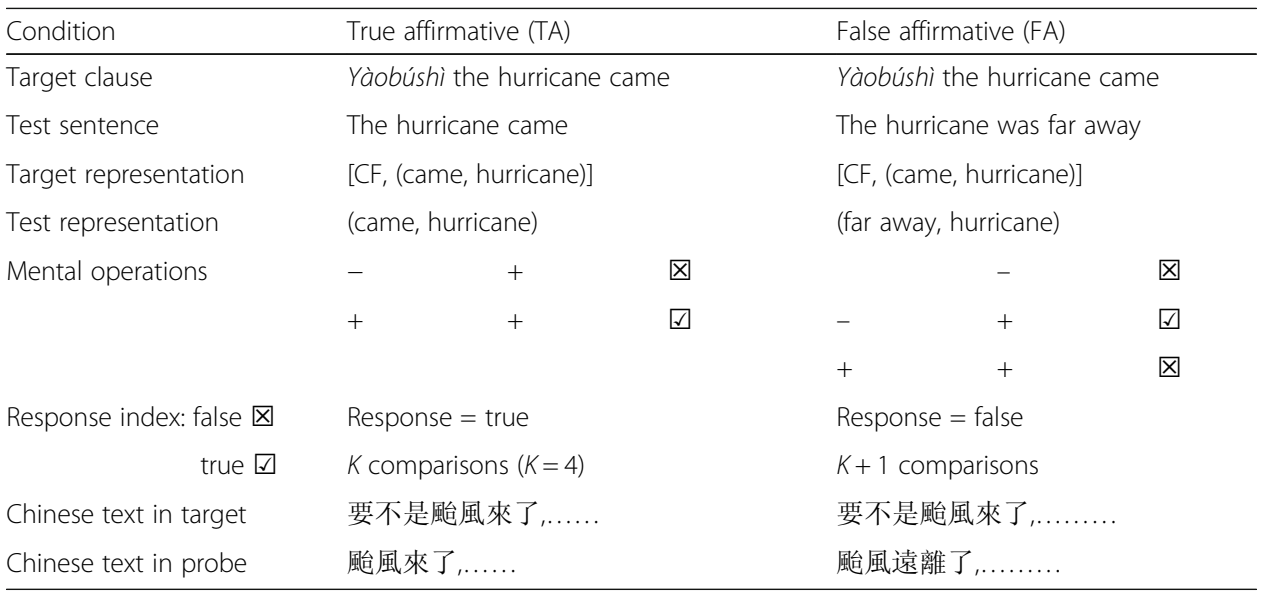

in the mental model to denote counterfactual thinking. For the same test sentences evaluating the comprehension of counterfactual target clauses, it is hypothesized that four mental operations are needed to compare the TA probe sentences but that five operations are needed for the FA sentences for the counterfactual target clauses. Thus, the TA condition is considered easier than the FA condition based on the mental processes necessary to derive meanings.

When the test sentences embed negation, they cause a mismatch and necessitate additional mental operations for factual-clause processing, as illustrated by Table 3. The TN sentences require five operations due to two mismatches of the inner proposition and the polarity, whereas the FN sentences require four comparisons. It is hypothesized that the FN condition is easier because the FN condition undergoes fewer mental operations compared to the TN condition. Together with Table 1, compared to factual clauses, the four types of probe sentences can be ordered in a continuum from the easiest to the most difficult as TA $<$ FA $<$ FN $<$ TN in terms of the hypothetical number of mental operations required. This order implies that when Chinese speakers process factual clauses in the mental model, polarity triumphs over the truth value in accessing the correct meaning.

Table 3 Hypothetical mental operation of negative probe sentences compared to factual clauses

\begin{tabular}{|c|c|c|c|c|c|}
\hline Condition & \multicolumn{2}{|l|}{ True negative (TN) } & \multicolumn{3}{|c|}{ False negative (FN) } \\
\hline Target clause & \multicolumn{2}{|l|}{ The hurricane came } & \multicolumn{3}{|c|}{ The hurricane came } \\
\hline Test sentence & \multicolumn{2}{|c|}{ The hurricane was not far away } & \multirow{2}{*}{\multicolumn{3}{|c|}{$\begin{array}{l}\text { The hurricane did not come } \\
\text { (came, hurricane)] }\end{array}$}} \\
\hline Target representation & \multicolumn{2}{|l|}{ (came, hurricane) } & & & \\
\hline Test representation & \multicolumn{2}{|c|}{ [Neg, (far away, hurricane)] } & \multicolumn{3}{|c|}{ [Neg, (came, hurricane)] } \\
\hline \multirow[t]{2}{*}{ Mental operations } & - & 凶 & - & + & \multirow[t]{7}{*}{ 凶 } \\
\hline & + & $\nabla$ & + & + & \\
\hline Response index: false $囚$ & + & & & & \\
\hline \multirow[t]{2}{*}{ true $\square$} & \multicolumn{2}{|l|}{ Response $=$ true } & \multicolumn{2}{|c|}{ Response $=$ false } & \\
\hline & \multicolumn{2}{|l|}{$K+4$ comparisons } & \multicolumn{2}{|c|}{$K+3$ comparisons } & \\
\hline Chinese text in target & \multicolumn{2}{|l|}{ 颱風來了,..........} & \multicolumn{2}{|c|}{ 颱風來了, ............ } & \\
\hline Chinese text in probe & \multicolumn{2}{|l|}{ 颱風沒有遠離, ...... } & \multicolumn{2}{|c|}{ 颱風沒有來,.......... } & \\
\hline
\end{tabular}


Compared with counterfactual clauses, the hypothetical negation embedded in the conditional conjunctive yàobúshì mismatches the negation in the probe sentences (see Table 4), which makes the process easier than affirmative probes. Hence, the order of mental processes from the easiest to the most difficult in accessing counterfactual clauses is TA $<$ FA $<$ FN $<$ TN because of the increasing number of mental operations of four, five, eight, and nine, respectively. This order implies that the polarity weighs more importantly than the truth value in processing counterfactual clauses. This processing order in counterfactuals is similar to that in handling factual clauses. The conjunction yàobúshì is not a combination of yàoshì and bú(shì) because the resulting order of the four types of conditions was different (cf. Hsu 2014). According to the findings in Hsu (2014), yàobúshì is a counterfactual conjunction leading to counterfactual interpretations in Chinese. This similarity has been demonstrated in Hsu (2014), and the models were repeated here for ease of comprehension.

\subsection{Predictions}

Given the reported results on college students in Hsu (2014), clauses and sentences with counterfactual conjunction yàobúshì were interpreted in the same ordering (TA, FA, FN, TN) as factual clauses and sentences based on the mental representations hypothesized by the constituent comparison model (rather than the other ordering in FN $<\mathrm{TN}<\mathrm{TA}<$ FA while hypothesizing yàobúshì as a combination of yàoshì and bú(shi)). As the junior high school teenagers and the elementary children were still developing their logical reasoning, they would need more time in comprehending counterfactual stimuli. Furthermore, based on Piaget's theory of cognitive development, the junior high group and the elementary group should be able to access the stimuli in the same ordering, the polarity outweighing the truth values.

\section{Results}

The participants' response times were taken as the comprehension time required to match probe sentences and test clauses. The response times were measured as the dependent variable (the percent correct in each group was high). The correct responses

Table 4 Hypothetical mental operation of negative probe sentences compared to counterfactual clauses

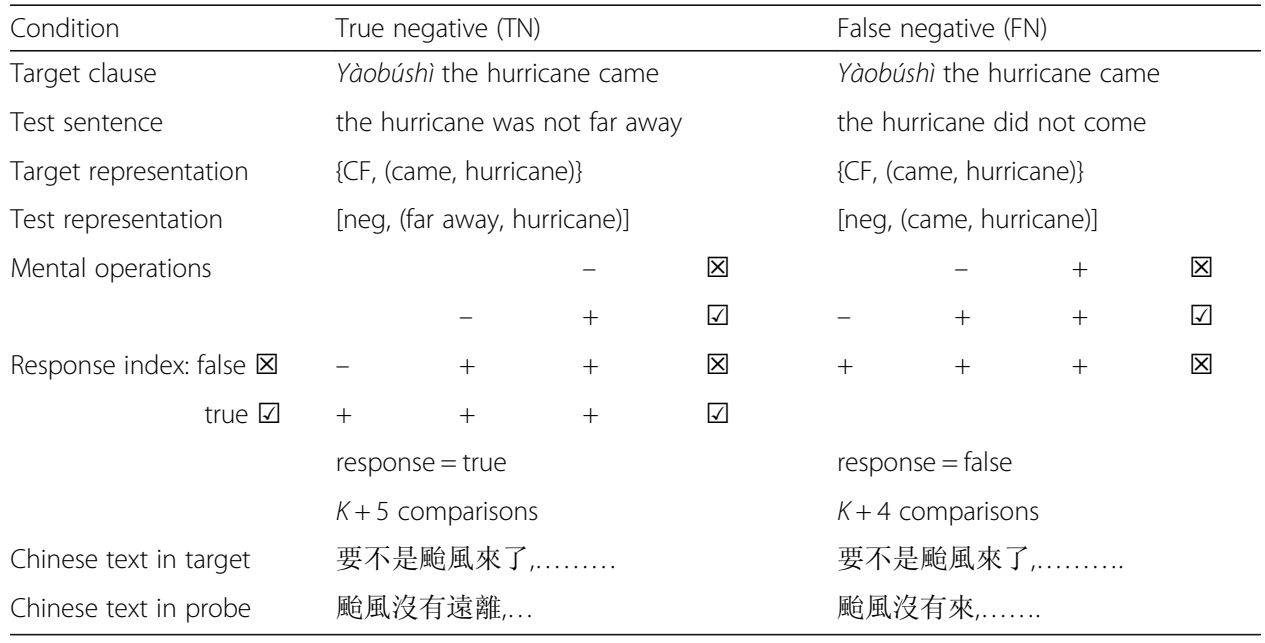


for the target clauses were subjected to analysis. A four-way repeated-measures ANOVA was conducted with the clause types (factual, counterfactual), truth values (true, false), and polarities (affirmative, negative) as within-participants factors together with each group (college students, junior high teenagers, elementary children) as a between-participants factor.

To comprehend the test sentences by matching the propositions embedded in representations, a four-way analysis of variances was conducted. Three between-participants factors reached significance. Faster responses to factual clauses $(1811 \mathrm{~ms})$ than to counterfactual clauses $(1935 \mathrm{~ms}$ ) were observed (main effect of clause type, $F(1,60)=32.73$, $p$ <.001). The probe sentences with true statements (TA, TN) had faster responses (1815 ms) than those with false statements (FA, FN) $(1931 \mathrm{~ms})$ (main effect of truth value, $F(1,60)=23.68, p<.001$ ). The affirmative sentences (TA, FA) were understood faster $(1696 \mathrm{~ms})$ than the negative sentences $(\mathrm{TN}, \mathrm{FN})(2050 \mathrm{~ms})(F(1,60)=214.41, p$ $<.001$ ). One within-participant factor was not significantly different (main effect of group, $F(2,60)=1.43, p>.05)$, suggesting that the college participants generally performed the fastest responses (1760 ms) compared to the other participant groups (the junior high teenagers $(1938 \mathrm{~ms})$ and the elementary children $(1921 \mathrm{~ms})$ ). No interaction with the group emerged, suggesting that the three groups showed similar patterns in the comprehension of counterfactual and factual clauses. An interaction between the truth value and polarity was observed $(F(1,60)=123.34, p<.001)$ with the simple main effect from the polarity difference on probe sentences of different truth values (TA < $\mathrm{TN}, t(62)=-15.87, p<.001$; FA $<\mathrm{FN}, t(62)=-4.62, p<.001)$ and from the truth value difference on probe sentences of different polarities (TA $<$ FA, $t(62)=-11.77$; FN $<$ TN, $t(62)=3.73$, both at $p<.001)$. The processing order for both clause types was TA $<$ FA $<\mathrm{FN}<\mathrm{TN}$, as proposed by the CCM, suggesting that counterfactual clauses with yàobúshì were processed in semantic-based representations as factual clauses across developmental stages, as shown in Fig. 1. No other interactions were observed.

Further analyses were conducted to investigate whether the counterfactual target clauses embedded in different test sentences caused a mental processing difference (the antecedents of $\mathrm{CC}$ sentences, hereafter, $\mathrm{CC} 1$; the consequents of $\mathrm{CC}$ sentences, $\mathrm{CC}$; the counterfactual target clause in CF sentences, CF1; and the counterfactual target

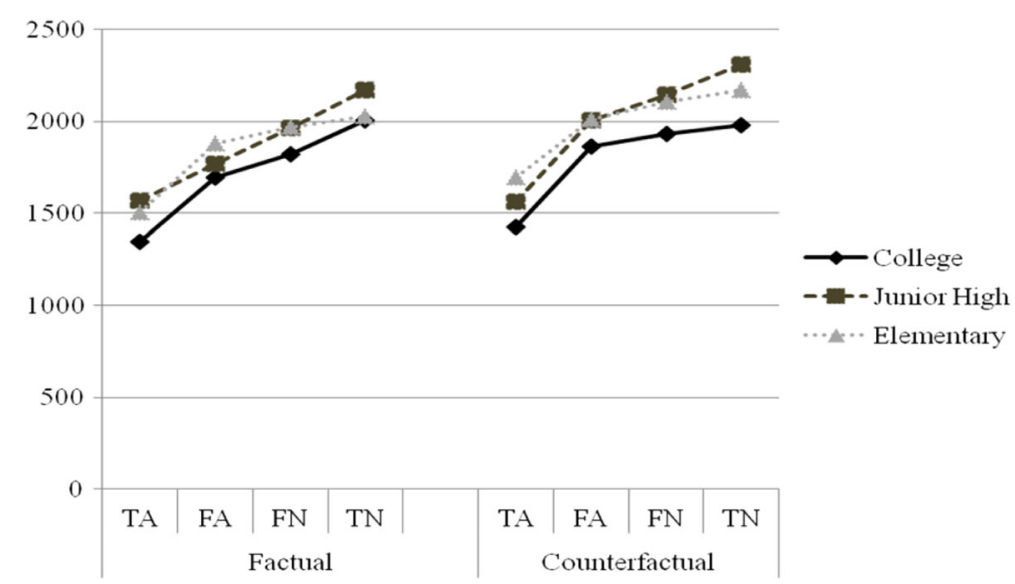

Fig. 1 The reaction times for factual clauses and counterfactual clauses in the three age groups 
clauses in FC sentences, FC2). The analysis included three within-participants factors (target clause type, truth value, polarity) together with groups as a between-participants factor. A four-way repeated-measures ANOVA was employed. The finding showed the processing order was the same in CC1 and CF1: TA $>$ FA $<$ FN $<$ TN. The detailed analyses were conducted as follows. A three-way interaction of the within-participants factors emerged $(F(3180)=14.51, p<.001)$, but no interaction with the groups was observed. The simple interaction of the truth value and polarity was significant in the CC1 $(F(1,62)=73.51, p<.001)$ and CF1 $(F(1,62)=42.67, p<.001)$ target clause types. Post hoc $t$ test comparisons revealed the truth value effect on probe sentences with different polarities and the polarity effect on probe sentences with different truth values (in CC1, TA $<\mathrm{TN}, t(62)=-9.79$, TA $<\mathrm{FA}, t(62)=-7.93, \mathrm{FN}<\mathrm{TN}, t(62)=4.17, p$ $<.001$; in CF1, TA $<\mathrm{TN}, t(62)=-10.46$, TA $<$ FA, $t(62)=-6.52$, FN $<\mathrm{TN}, t(62)=2.75$, $p=.008)$. No simple interaction in the CC2 and FC2 target clause types was observed. In sum, the three groups processed counterfactual target clauses differently according to the antecedents and consequents. The antecedents in non-canonical sentences (CF1) were processed in the same way as the antecedents in canonical sentences (CC1), as illustrated in Figs. 2 and 3.

Further investigation on the possible target clause position effect in counterfactual comprehension was analyzed. A four-way repeated-measures ANOVA was conducted with the target clause positions (antecedents as clause 1, consequents as clause 2), truth values (true, false), and polarities (affirmative, negation) as the within-participants factors, together with the groups (college students, junior high teenagers, elementary children) as the between-participants factor. The results revealed a three-way interaction of the within-participants factors without the group effect $(F(1,60)=39.70, p<.001)$. One of the simple interactions, from the interaction of the truth values and polarities on clause 1 , was significant $(F(1,62)=98.53, p<.001)$. The simple main effect was from the truth value effect on the probe sentences with distinct polarities and the polarity effect on the probe sentences with different truth values $(\mathrm{TA}<\mathrm{TN}, t(62)=-12.51$; $\mathrm{TA}<\mathrm{FA}, t(62)=-9.35$; $\mathrm{FN}<\mathrm{TN}, t(62)=4.70$; all $p<.001)$. No interaction on clause 2 was observed. Other simple

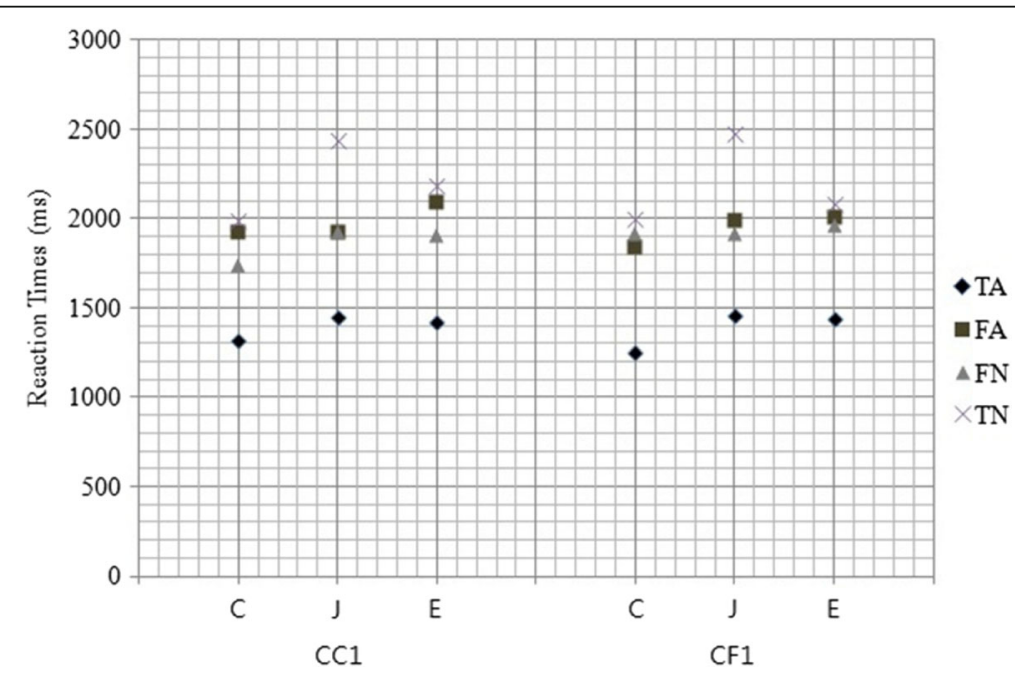

Fig. 2 The reaction times of the four probe sentence types for counterfactual target clauses in CC1 and CF1 in the three groups 


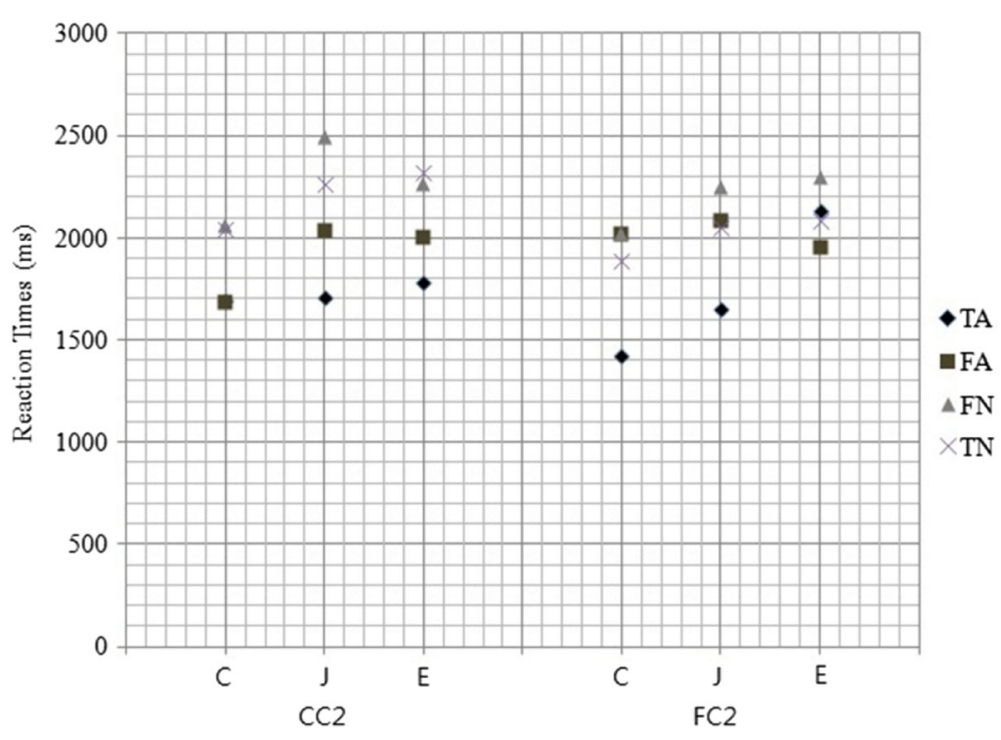

Fig. 3 The reaction times of the four probe sentence types for counterfactual target clauses in CC2 and FC2 in the three groups

interactions of the target clause positions and polarities were observed on the sentences with true statements $(F(1,62)=33.50, p<.001)$ and on the sentences with false statements $(F(1,62)=11.93, p=.001)$. Post hoc $t$ test comparisons revealed that the target clause position effect (clause $1<$ clause 2) on the affirmative probes with true statements (TA1 < TA2, $t(62)=-5.62, p<.001)$ and on the negative probes with false statements (FN1 < FN2, $t(62)=-4.49, p<.001)$ was significantly observed. These findings were consistent with the previous results that matched propositions between the target counterfactual clauses in which the sentences facilitated processing time in the mental model (see Fig. 4).

In sum, the analyses yielded no group difference, showing adult-like counterfactual processing of 12-year-old children. Better comprehension (faster responses) of factual target clauses, affirmative clauses, and true statements was observed compared to

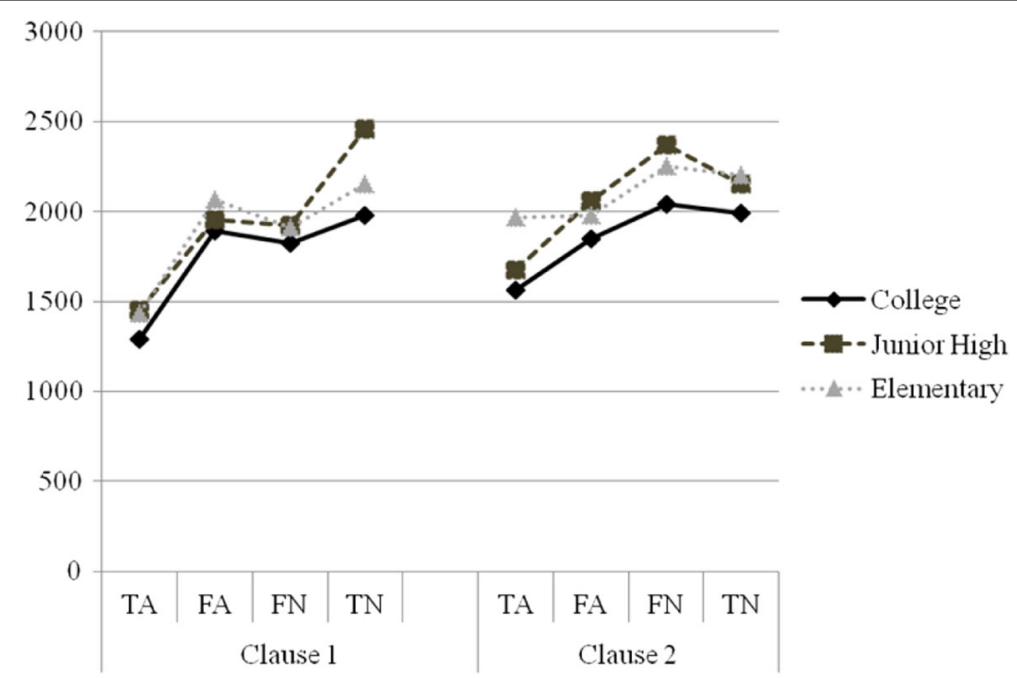

Fig. 4 The reaction times of counterfactual target clauses in antecedents (clause 1) and consequents (clause 2) of the three groups 
counterfactual target clauses, negative clauses, and false statements. Both canonical and non-canonical counterfactual clauses were processed similarly, which is inconsistent with the proposals of this study based on the CCM (showing TA $<$ FA $<$ FN $<$ TN ordering). Moreover, only antecedent counterfactual target clauses confirmed the processing ordering, but not consequent counterfactual target clauses, suggesting the counterfactual conjunction yàobúshì in the beginning position of a sentence led to contrary-to-fact thinking. This could be the evidence to argue against the necessary association of yàobúshì and collocates ((就)(不)會, (jiù)(bú)huì and many others) to obtain the counterfactual interpretations (Jing-Schmidt 2017).

\section{Discussion and conclusion}

The conjunction yàobúshì is a counterfactual marker in Chinese, as in

\section{(13) 要不是我遲到了, 車子就不會開走了 yàobúshì_wǒ_chídào_le, chēzi_jiù_búhuì_kāizǒu_le if-it-were-not_I_late_ASP, car_only_would-not_drive-away_ASP If it was not that I had been late, the car would not have been driven away}

The results were in line with the findings in previous studies coercing 如果 rúguó 'if' and 沒有 méiyóu 'not' in antecedent clauses, together with the negation 不會 búhui 'not' and the aspect marker $l e(了)$ in consequent clauses, as in

(14) 如果我沒有遲到, 車子就不會開走了

rúguǒ_wǒ_méiyǒu_chídào, chēzi_jiù_búhuì_kāizǒu_le
if_I_not_late, car_only_would-not_drive-away_ASP

If I had not been late, the car would not have been driven away

(Hsu 2013). Supporting evidence was obtained from different developmental stages, confirming yàobúshì as a counterfactual conjunction. By correctly constructing the representations of propositions and the relations between propositions, interpretations of beliefs are reached (Wimmer and Perner 1983). In Chinese counterfactuality, through the counterfactual conjunction yàobúshì, factual information is enabled in antecedents and the imaginary outcomes in consequents. Instead of using subjunctive moods as mediators, the mental processes of reality/beliefs and imaginations/desires in theory of mind tightly link counterfactual conditionals with yàobúshì in Chinese.

Developmental data provided further support to the findings in Hsu (2014) that the conditional conjunctive yàobúshì cannot be understood as the combination of a conditional marker 要是 yàoshì 'if' (and the negation 不(是) bú(shì) 'not' or méiyǒu. Based on the Academia Sinica Balanced Corpus of Modern Chinese (中央研究院漢語平衡語料庫, Chen et al. 1996; Huang et al. 2017), most sentences with the combination of yàoshì and bú(shi) or méiyǒu simply describe possible conditional situations. For instance, consider

(15) 要是不合身怎麼辦?

$$
\begin{aligned}
& \text { yàoshì_bù__héshēn_zěmo_bàn } \\
& \text { if_not_fit_how_do } \\
& \text { If it is unfit, what can I do? }
\end{aligned}
$$


(16) 要是沒有颱風, 差不多每天都是一樣

yàoshì_méiyǒu_táifēng, chābùdūo_měitiān_dōu_shì_yíyàng

if_not_typhoon, almost_every-day_all_is_the-same

If there is no typhoon, there is no difference in daily life

(17) 要是還有不認識的字, 就查字典

yàoshì_háiyǒu_búrènshì_de_zì, jiù_chá_zìdiăn

if_still-have_do-not-know_DE_word, only_look-up_dictionary

If there are unknown words, you can look them up in a dictionary

Yàobúshì is proposed as a single unit, making counterfactual expression possible, but it is not equivalent to the combination of yàoshì-bú(shì) or yàoshì-méiyǒu. This offline investigation provides support to our psycholinguistic findings that the mental representations of counterfactuals with yàobúshì in Chinese are not embedded negations but that a counterfactual conditional conjunction opens a door of imagination and allows speakers to enter into a hypothetical world. There are 45 out of 75 sentences (60\%) with yàobúshì in the corpus indicating counterfactual meaning with imaginary negative consequences, as in

(18) 要不是大白鵝趕來救他, 早就送掉一條命了

yàobúshì_dàbáiér_gănlái_jiùtā, zăojiù_sùngdiào_yìtiáomìng_le

if-it-were-not_big-white-goose_hurrily-come_save-him, already-at-an-earlier-

time_give-away_one-CL-life_ASP

If it was not that a big goose had come to save him, he would have lost his life

(19) 要不是同學和房東熱心的幫助我, 真不知道該怎麼辦

yàobúshì_túngxúe_hé_fángdūng_rèxīn_de_bāngzhù_wǒ, zhēn_bùzhīdào_ gāi_zěmobàn

if-it-were-not_classmate_and_landlord_enthusiastically_DE_help_I, really_don't-know_should_how-to-do

If it was not that classmates and the landlord had helped me enthusiastically, I

would have never known how to manage it

(20) 要不是趙樹理, 我們早就餓死了

yàobúshì_zàoshùlǐ, wǒmén_zǎojìu_èsǐ_le

if-it-were-not_Zàoshùlǐ (name), we_already-at-an-earlier-time_hungry-to-die_ASP

If it was not that we had been with Zaoshuli('s help), we would have been starved

to death

(21) 要不是我撥了電話, 恐怕你連中飯都省了

yàobúshì_wǒ_būo_le_dìanhùa, kŭngpà_nǐ_líen_zhūngfàn_dōu_shěng_le if-it-were-not_I_call_ASP_telephone, I-was-afraid_you_even_lunch_all_ spare_ASP

If it was that I had made the phone call, you would have missed the lunch

Nineteen out of 75 sentences (25\%) with yàobúshì in the corpus denote counterfactual meaning with narrator's desires, for instance, 
(22) 要不是春樹也參加了同一個補習班, 我也不想去呢

yàobúshì_chūnshù_yè_cānjīa_le_tóngyígè_bǔxíbān, wǒ_yě_bùxǐang_qù_ne if-it-were-not_Chūnshù (name)_also_attend_ASP_the-same-one_cramschool, I_also_don't-want_go_ASP

If it was not that Chünshù had attended the same cram school, I would not have been there

(23) 要不是我運氣不好, 現在經理位子應該是我坐的 yàobúshì_wǒ_yùnqì_bùhăo, xìanzài_jīnglì_wèizi_yīnggāi_shìwǒ_zùo_de if-it-were-not_I_luck_not-good, now_manager_position_should_be-mine_ sit_DE

If it was not that I had had bad luck, I would have been in the post as a manager

(24) 要不是氣氛詭異, 接下來我一定拍手逗他 yàobúshì_qìfèng_gǔiyì, jiēxiàlái_wǒ_yídìng_pāishǒu_dòutā if-it-were-not_atmosphere_weird, next_I_must_clap-hands_make-him-laugh If it was not that the atmosphere had become weird, my next act would have clapped my hands to make him happy

(25) 要不是辛巴誕生, 王位的繼承人應該是我 yàobúshì_xīnbā_dànshēng, wángwèi_de_jìchéngrén_yīnggāi_shìwǒ if-it-were-not_Xīnbā (name)_born, king-position_DE_heir_should_be-mine If it was not that Xinbā had been born, I would have been second to none

Other sentences with yàobúshì do not entail contrary-to-fact interpretation, such as making contrasts $(8 / 75,0.11 \%)$ as in

(26) 要不是向敵人打信號, 就是在吸引敵人的砲火 yàobúshì_xìang_dírén_dǎxìnhào, jìushì_zài_xīyǐn_dírén_de_pàohǔo if-it-were-not_toward_enemy_send-signals, exactly_ASP_appeal-to_enemy_ DE_bombfire

If it was not that (someone) lights signals to the enemies or appeals to the enemies' attacks

(27) 要不是已經退休, 就是已過事業真峰而到了該交棒的時候

yàobúshì_yìīing_tuèixiū, jìushì

_yìgùo_shìyè_dīanfēng_érdàole_gāi_jīaobàng_de_shíhòu

if-it-were-not_already_retire, exactly_already-passed_career_top_thenmoved-to_should_pass-on_DE_timing

If it was not that (they) had already retired or had passed the top of their career and had to find someone to inherit it

standing for if only $(1 / 75,0.13 \%)$, as in

(28) 只要不是離家太遠, 阿春總是擠在台下人堆裡搶著第一個拍手 zhǐyào_búshì_líjīa_tàiyǔan, āchūn_zŭngshì_jǐ_zài_táixià_rénduīlì_qǐang_zhe_dìyīge_pāishǒu 
if-only_not_leave-home_too-far, Āchūn (name)_always_crowd-

in_ASP_below-stage_in-the-crowd_hurry_ASP_the-first_clap-hands

If only (the show) is not far away from Ächün's house, he is always in the crowd to

be the first one clapping his hands

Two uses have no context $(2 / 75,0.27 \%)$. These analyses suggest that most, although not all, sentences with yàobúshì are related to counterfactual expressions.

From the developmental trends, the negation 不 bù 'not' in yàobúshì does not function as a negator, but it is combined with yàoshì as a counterfactual conjunction to guide Chinese speakers into a contrary-to-fact world. This paper proposes that the conditional conjunction yàobúshì is a counterfactual conjunction in pragmatic use as a frozen expression without negation. Chinese speakers state counterfactuals by describing expected hypothetical situations as their desires/imagination in their minds, which are alternatives to actual situations. Simultaneously, Chinese speakers admit the existence of real situation and describe it in the antecedent as a premise or background to create a contradiction in a counterfactual conditional with yàobúshì. Hence, two representation levels coexist in the mental model: the actual belief and the opposite desire in imagination. Uttering counterfactuality with yàobúshì explicitly expresses desired outcomes that are contradictory to real conditions.

The construction of false beliefs takes time to develop, as Wimmer and Perner (1983) demonstrated in differentiation of deceitful from truthful states from the age of six onward. The participants received two stories describing a protagonist, Maxi, who observed his mother bring chocolate back home from a shopping trip and put it into a blue cupboard. Later, Maxi went out to the playground without witnessing his mother take out the chocolate and grate it to make a cake. Subsequently, his mother put the chocolate in a green cupboard. Then, Maxi came back from the playground and wanted to eat it. The participants were asked a belief question of "where will Maxi look for the chocolate?", a reality question of "where is the chocolate really?", and a memory question of "do you remember where Maxi put the chocolate in the beginning?". Before the reality question and the memory question were posed, two different narrations about mental states of competition or cooperation were provided to investigate whether the participants successfully inferred the mental states and uttered the expected responses. In the competitive condition, Maxi's brother showed up in the kitchen to get the chocolate, but Maxi did not want to share it. So, Maxi would tell him a different place from the original place where his mother had put it. In the cooperative condition, Maxi was too small to reach up to the cupboard where the chocolate was placed. At that time, Maxi's grandpa came to visit him, so Maxi asked for help from him. If the participants successfully inferred the mental state of the protagonist in competition, they were expected to respond with the green cupboard, which was the correct answer. However, if the cooperative state was reasoned, the participants would respond that the blue cupboard was where Maxi's mother actually put the target, which would be the wrong answer. The participants had to understand the belief of the protagonist and reason the conditions. Three groups of participants with different ages took part in the study: those aged four to five, six to seven, and eight to nine. The results revealed that children older than six tended to reply with a deceptive, incorrect answer of where the chocolate was, in their minds refusing to share (competitive condition), but they 
responded to the grandfather with the correct answer in their minds (cooperative condition). Most of the time, the young group replied with the place where Maxi's mother had put the chocolate later after grating it, regardless of the different conditions of mental states, suggesting a lack of mentalizing ability in the early stage of development. The children 6 years of age and older showed deceitful behaviors in the competitive condition but a cooperative attitude with the grandfather. A follow-up study confirmed that the failure of young participants to reason regarding the protagonist's mental states was not because they reacted to questions too quickly, leading to low accuracy. From Wimmer and Perner's results (Wimmer and Perner 1983), it is clear that 6-year-old children, but not younger children, have developed reasoning capacities regarding other people's minds.

Our study with reading materials revealed that the elementary participants understood counterfactuals with yàobúshì, inferred mental states from expressions of reality/ beliefs and imaginations/desires, and linked them to theory of mind without difficulty, similarly to college students. Unlike the significantly slow response latencies of the elementary students to respond to coercive counterfactual reading with rúguǒ, méiyǒu, búhuì, and le in Hsu (2013), elementary students develop an adult-like ability early to comprehend the counterfactual conjunction yàobuishi. As revealed by the protocols of theory of mind in location change (Sally-Anne story) and content change (Smarties test), 4-year-olds possess this cognitive ability and pass false belief tests of ability to infer the mental states of others. Our elementary participants were, on average, 12year-olds, who have developed reasoning abilities. We leave exploration of early childhood ( $<2$ years old) development on Chinese counterfactual reasoning with reading materials and its association with theory of mind for future studies. Other potential counterfactual conjunctions, such as 早知道 zăozhidao 'had it known' or classical Chinese lexical words such as 假使 jiăsh ̌r 'if', 若使ruòshı̌ 'if', and 微 wéi 'if not', need psycholinguistic support regarding this availability.

With subjunctive moods in Chinese, it is proposed that Chinese speakers emphasize contrasts of realities/beliefs and desires/imaginations in comprehending counterfactuals. This proposal is in line with a study showing that adults do not fully apply theory of mind in comprehension (Keysar et al. 2003). In Keysar et al. (2003), a participant and a director were tested in a communication game. The participant had to react to the director's instructions concerning the following pair of objects: one visible intended object and the other an invisible hidden object in a brown bag. Two studies were conducted as follows: (1) only the participants knew the objects inside of the bags, while the directors had no idea about the object, and the participants realized the director's ignorance; (2) the directors were informed that certain objects were inside of the bags, but in actuality, different objects were in the bags, and the participants knew the directors had false beliefs about the contents of the bags. The rationale of the tests' design was to investigate whether the participants would incorporate the directors' states of knowledge of the bag into their responses. For example, a participant was instructed by a director to move the tape from a visible cassette tape and an invisible hidden roll of tape in the bag. Measurements of behavioral responses regarding executing actions and eye tracking fixation plus gaze duration were perspective-taking indexes. The results showed that under situations of the directors' ignorance and false beliefs, the participants $(71 \%)$ actually moved the invisible hidden objects at least once. Compared to the 
baseline conditions, i.e., truly different categories of objects (e.g., a battery) from targets (e.g., a roll of tape) in brown bags, the participants fixated on the hidden objects five times more, and the gaze duration was six times more in the experimental conditions. Moreover, the decision time (measured as final fixation on the intended objects) was delayed in $82 \%$ of the participants or doubled in the experimental conditions compared to the baseline conditions. These findings indicated that adult participants did not consider the directors' perspectives of ignorance or false beliefs of hidden objects in responding to the instructions, suggesting sparseness in the application of theory of mind in adults.

In Chinese, counterfactuals without a subjunctive mood, but instead containing the lexical expression yàobúshì, differentiate alternative situations from reality. In English, the subjunctive mood is the indicator for denoting contrary-to-fact thought. However, in Chinese, using the counterfactual conjunctive yàobúshi at the lexical level achieves the same function. Chinese speakers use yàobúshì to express hypothetical situations by stating the real situation as a proposition (Hsu 2014). Counterfactual reasoning requires the construction of the mental model of contrary-to-fact unreality for processing and requires two cognitive operations: first, entering a possible world, and then, differentiating the time frame of the event in the possible world (Hsu 2013). In counterfactual reasoning, comprehenders make inferences regarding events that are contrary to past events. To achieve successful counterfactuality and comprehension of counterfactual conditionals, one must first combine reality with alternatives and then understand this reality as truth. Reality plays an important role in counterfactual reasoning. The mental model is based on an imagined event, which itself is dependent on reality. In English, the processes of entering a possible world are by comprehending the conditional marker if and differentiating time frames through the use of the subjunctive mood to clarify counterfactual reasoning. In English, these two cognitive operations are achieved through linguistic elements. However, in Chinese, there is no linguistic inflection that parallels the English subjunctives. Because of this morphological simplicity, any if-then construction in Chinese may refer to mental models of reality, hypothetical/imaginative unreality, or counterfactual unreality. In Chinese, a possible world is constructed through conditional conjunctives such as yàobúshì. Then, comprehenders differentiate time frames through tightly linking realities/beliefs and alternatives/desires. With application of theory of mind, hence, various coercions and collocations can make Chinese counterfactuals possible. In contrast, if salient morphological inflections could serve as mediations to reach counterfactuality, there would be less or no need to apply theory of mind in counterfactual reasoning. Comparisons of counterfactual processing in Chinese and English with similar stimuli in the same study need to be employed in the future.

\section{Endnotes}

${ }^{1}$ Academia Sinica Balanced Corpus of Modern Chinese 中央研究院漢語平衡語料庫 Available at http://asbc.iis.sinica.edu.tw/. Accessed 10 April 2016 and 20 July 2017.

Acknowledgements

The author is grateful for all participants who took part in this study and would also like to thank the reviewers of the earlier draft. Additionally, the author would like to thank the National Yang Ming University, Fu-He Junior High School, and Qing-Jiang Elementary School in Taiwan for supporting this study. 


\section{Competing interests}

The author declares that she has no competing interests.

\section{Publisher's Note}

Springer Nature remains neutral with regard to jurisdictional claims in published maps and institutional affiliations.

\section{Received: 31 July 2017 Accepted: 3 November 2017}

Published online: 15 December 2017

\section{References}

Baron-Cohen, Simon, Alan M. Leslie, and Uta Frith. 1985. Does the autistic child have a "theory of mind"? Cognition 21(1): 37-46.

Carpenter, Patricia A. 1973. Extracting information from counterfactual clauses. Journal of Verbal Learning and Verbal Behavior 12(5): 512-521

Carpenter, Patricia A., and Marcel A. Just. 1975. Sentence comprehension: A psycholinguistic processing model of verification. Psychological Review 82(1): 45-73.

Chase, William G., and Herbert H. Clark. 1972. Mental operations in the comparison of sentences and pictures. In Cognition in learning and memory, ed. Gregg Lee W., 205-232. New York: Wiley.

Chen, Keh-jiann, Chu-Ren Huang, Li-ping Chang, and Hui-Li Hsu. 1996. Sinica corpus: Design methodology for balanced corpora. In Proceeding of the 11th Pacific Asia conference on language, information and computation, ed. Byung-Soo Park and Jong-Bok Kim, 167-176. Seoul: Kyung Hee University.

Clark, Herbert H., and William G. Chase. 1972. On the process of comparing sentences against pictures. Cognitive Psychology 3(3): 472-517.

Eifring, Halvor B. 1988. The Chinese counterfactual. Journal of Chinese Linguistics 16(2): 193-218.

Flobbe, Liesbeth, Rineke Verbrugge, Petra Hendrinks, and Irene Krämer. 2008. Children's application of theory of mind in reasoning and language. Journal of Logic, Language, and Information 17(4): 417-442.

Frye, Douglas, Philip D. Zelazo, and Tibor Palfai. 1995. Theory of mind and rule-based reasoning. Cognitive Development 10(4): 483-527.

Hsu, Ching-Fen. 2013. Counterfactual reasoning embodied in cognition rather than linguistic forms: Evidence from a developmental study in Chinese. Journal of Chinese Linguistics 41(2): 292-316.

Hsu, Ching-Fen. 2014. Semantic-based mental representation of Chinese counterfactuals: Evidence from a psycholinguistic study of Yaobushi. Language and Linguistics 15(3): 391-410.

Huang, Chu-Ren, Shu-Kai Hsieh, and Keh-Jiann Chen. 2017. Mandarin Chinese words and parts of speech: A corpus-based study. London: Routledge.

Jiang, Yan. 2018 To appear. Chinese and counterfactual reasoning. In The Routledge handbook of Chinese applied linguistics, ed. Chu-Ren Huang, Zhuo Jing-Schmidt, and Barbara Meisterernst. London: Routledge.

Jing-Schmidt, Zhuo. 2017. What are they good for? A constructionist account of counterfactuals in ordinary Chinese. Journal of Pragmatics 113: 30-52.

Keysar, Boaz, Shuhong Lin, and Dale J. Bar. 2003. Limits on theory of mind use in adults. Cognition 89(1): 25-41.

Leslie, Alan M., and Laila Thaiss. 1992. Domain specificity in conceptual development: Neuropsychological evidence from autism. Cognition 43(3): 225-251.

Liu, Lisa G. 1985. Reasoning counterfactually in Chinese: are there any obstacles? Cognition 21(3): 239-270.

Piaget, Jean. 1936. Origins of intelligence in the child. London: Routledge \& Kegan Paul.

Premack, David, and Guy Woodruff. 1978. Does the chimpanzee have a theory of mind? Behavioral and Brain Sciences 1(4): 515-526.

Rafetseder, Eva, and Josef Perner. 2010. Is reasoning from counterfactual antecedents evidence for counterfactual reasoning? Thinking and Reasoning 16(2): 131-155.

Riggs, Kevin J., Donald M. Peterson, Elizabeth J. Robinson, and Peter Mitchell. 1998. Are errors in false belief tasks symptomatic of a broader difficulty with counterfactuality? Cognitive Development 13(1): 73-90.

Roese, Neal J. 1997. Counterfactual thinking. Psychological Bulletin 121(1): 133-148.

Sterelny, Kim. 1990. The functionalist theory of the mind. In Representational theory of mind: An introduction, 1-18. Cambridge: Blackwell.

Wimmer, Heinz, and Josef Perner. 1983. Beliefs about beliefs: Representation and constraining function of wrong beliefs in young children's understanding of deception. Cognition 13(1): 103-128. 